\title{
Barriers perceived by family doctors in the implementation of medical education for the prevention of mental health disorders in the perinatal period
} Barierele percepute de medicii de familie în realizarea educației medicale
pentru prevenirea tulburărilor de sănătate mintală în perioada perinatală

\author{
Irina Angela RADU ${ }^{1}$, lleana Anca EFRIM², Dumitru MATEI ${ }^{1,3}$ \\ ${ }^{1}$ Disciplina Medicină de Familie, Universitatea de Medicină şi Farmacie „Carol Davila“, București, România \\ ${ }^{2}$ Cabinet individual de medicină de familie, Île-de-France, France \\ ${ }^{3}$ INSMC „Alessandrescu-Rusescu“, București, România
}

\begin{abstract}
Objective. The prevention of mental health disorders and the promotion of mental health are valuable tools for reducing the incidence and prevalence of mental health disorders. These tools can be used by family physicians, early, since the perinatal period. The objective of the research was to identify the barriers perceived by family doctors in communicating preventive measures for mental health disorders, through medical education, to the young patient in the preconception period and the pregnant patient.

Method and results. The research was conducted on the basis of a self-administered, anonymized questionnaire. The target group was represented by 153 family doctors from Romania. The answers to the questions aiming to identify the possibility for the family doctors to do medical education for the prevention of mental health disorders of the future conception product, in the young woman, in the preconception period as well as in the pregnant woman were analyzed. The results showed that $32.89 \%$ of respondents express their willingness to do medical education to prevent mental health disorders of the future product of conception in women in preconception and $41.45 \%$ in pregnant women. The ranking of the reasons chosen for the lack of availability to communicate preventive measures during the consultation, in the patient in the preconception period, puts on the first place the lack of necessary work tools (45.10\%), and on the second place, the lack of knowledge of communication techniques for such situations (22.55\%), and on the third, the fact that patients do not come to the doctor with such questions (17.65\%). In pregnant women, the perceived barriers are: lack of necessary work tools (47.19\%), lack of knowledge of communication techniques for such situations $(22.47 \%)$, and the fact that patients do not come with such questions to the family doctor (14.67\%).

Conclusions. Family physicians express their willingness to communicate preventive measures and to promote mental health through early applied medical education, since the perinatal period. The research reveals that the lack of knowledge of communication techniques, the lack of adapted work tools and the fact that patients do not come with such questions to the family doctor are the main barriers perceived by family doctors.
\end{abstract}

Keywords: family medicine, mental health, prevention, medical education, preconception, perinatal 


\section{REZUMAT}

Obiectiv. Prevenția tulburărilor de sănătate mintală și promovarea sănătății mintale reprezintă instrumente valoroase pentru reducerea incidenței și prevalenței tulburărilor de sănătate mintală. Aceste instrumente pot fi utilizate de medicii de familie precoce, încă din perioada perinatală. Obiectivul cercetării a fost identificarea barierelor percepute de medicii de familie în demersul comunicării măsurilor preventive pentru tulburările de sănătate mintală prin educație medicală la pacienta tânără aflată în perioada de preconcepție și la pacienta gravidă.

Metodă și rezultate. Cercetarea a fost realizată pe bază de chestionar autoadministrat, anonimizat. Lotul țintă a fost reprezentat de 153 de medici de familie din România. S-au analizat răspunsurile intrebărilor care au avut ca obiectiv identificarea posibilității medicilor de familie de a face educație medicală pentru prevenția tulburărilor de sănătate mintală ale viitorului produs de concepție la femeia tânără aflată în perioada de preconcepție, precum și la femeia gravidă. Rezultatele au arătat că 32,89\% dintre respondenți își exprimă disponibilitatea de a face educație medicală pentru prevenirea tulburărilor de sănătate mintală ale viitorului produs de concepție la femeia aflată in perioada de preconcepție și $41,45 \%$ la femeia gravidă. Clasamentul motivelor alese pentru lipsa disponibilității de a comunica măsuri preventive în cursul consultației la pacienta aflată în perioada de preconcepție pune pe primul loc lipsa instrumentelor de lucru necesare (45,10\%), pe al doilea loc, lipsa cunoașterii tehnicilor de comunicare pentru astfel de situații (22,55\%), iar pe al treilea, faptul că pacientele nu vin la medic cu astfel de întrebări (17,65\%). La femeia gravidă, bareierele percepute sunt: lipsa instrumentelor de lucru necesare $(47,19 \%)$, lipsa cunoașterii unor tehnici de comunicare pentru astfel de situații $(22,47 \%)$, precum și faptul că pacientele nu vin cu astfel de întrebări la medicul de familie $(14,67 \%)$.

Concluzii. Medicii de familie își exprimă disponibilitatea de a comunica măsuri preventive și de a promova sănătătea mintală prin educație medicală aplicată precoce, încă din perioada perinatală. Cercetarea relevă faptul că lipsa cunoașterii unor tehnici de comunicare, lipsa unor instrumente de lucru adaptate și faptul că pacientele nu vin cu astfel de întrebări la medicul de familie reprezintă principalele bariere percepute de medicii de familie.

Cuvinte cheie: medicină de familie, sănătate mintală, prevenție, educație medicală, preconcepție, perinatal

\section{INTRODUCERE}

Medicina de familie reprezintă una dintre resursele de bază ale sistemului de sănătate, fiind specialitatea care are abilitatea de a rezolva aproximativ $90 \%$ dintre nevoile de asistență medicală ale populației, cu costuri minime [1]. Această realitate este întărită și de faptul că medicul de familie, prin natura formării sale profesionale și specificul practicii de cabinet, are aptitudini și cunoștințe care îi oferă posibilitatea să rezolve o paletă variată de probleme de sănătate în comunitatea pe care o îngrijește [2]. Medicul de familie este medicul de prim contact, care asigură asistență medicală primară, indiferent de patologia, vârsta, genul, etnia sau statutul social și economic al pacientului $[1,2]$. Spre deosebire de alte specialități medicale, care de-a lungul timpului s-au supraspecializat, limitându-și astfel îngrijirile la un singur organ sau un singur tip de patologie, medicina de familie s-a dezvoltat continuu, răspunzând provocării de a asigura starea de sănătate a pacientului ca întreg, atât din punct de vedere somatic, cât și psihologic [1]. Starea de sănătate mintală este definită de Organizația Mondială a Sănătății ca fiind parte esențială a stării de sănătate. Practic, nu putem discuta despre sănă- tatea individului fără sănătatea mintală, sănătatea mintală fiind definită ca absența tulburărilor psihice [3].

La nivel mondial, milioane de oameni suferă de tulburări de sănătate mintală, mulți dintre aceștia neprimind tratament sau nefiind nici măcar diagnosticați. Conform datelor furnizate de Organizația Mondială a Sănătății, 4 din 5 persoane din țările cu venituri mici și medii nu primesc îngrijiri medicale, deși necesită asistență medicală pentru tulburări de sănătate mintală, tulburări neurologice sau tulburări legate de abuzul de substanțe [4]. Soluția pentru acești pacienți este oferită de Organizația Mondială a Sănătății, care, împreună cu Organizația Mondială a Medicilor de Familie, propune integrarea serviciilor de sănătate mintală la nivelul asistenței medicale primare [5]. Îngrijirea de lungă durată a pacienților cu tulburări de sănătate mintală pune o presiune uriașă pe sistemele de sănătate și, de aceea, integrarea sănătătii mintale la nivelul medicinei de familie este imperios necesară, atât pentru creșterea accesului pacienților la asistență medicală (prevenție, diagnostic, tratament și monitorizare), cât și pentru eficientizarea costurilor $[5,6]$. Actor principal pe scena asistenței medicale primare, medicul de familie este medicul cu mul- 
tiple roluri: rol preventiv, rol curativ, rol de coordonator al pacientului cu tulburări de sănătate mintală în sistemul de sănătate, rol de manager și, nu în ultimul rând, rol de comunicator $[1,2]$. Comunicarea medic-pacient reprezintă o abilitate esențială pentru practica medicală și un element central al competenței clinice medicale, aceasta din urmă fiind alcătuită din 4 componente fundamentale: baza de cunoștințe, abilitățile de comunicare, protocolul de examinare fizică a pacientului și abilitățile de rezolvare a problemelor $[7,8]$. Abilitățile de comunicare trebuie învățate și menținute prin educație continuă pe parcursul întregii vieți profesionale a medicului, acestea nefiind o trăsătură de personalitate $[7,8]$. Dacă ne referim mai specific la comunicarea medicului de familie cu pacientul cu tulburări de sănătate mintală, aceasta poate fi o provocare atât pentru medic, cât și pentru pacient, fiind necesare competențe particulare de comunicare, ce pot fi obținute atât prin cursuri dedicate, cât și prin experiență profesională dobândită în timp [9]. Talentul de a comunica este esențial și obligatoriu în activitatea medicului de familie, acesta rafinându-și cunoștintele din domeniul comunicării pe tot parcursul carierei. Abilitățile de comunicare ale medicului de familie se întâlnesc atât în momentul stabilirii diagnosticului și a strategiei terapeutice, dar și în situația în care face educație medicală pentru promovarea sănătății, atât somatică, cât și mintală, în cursul unei consultații la pacienții pe care îi îngrijește $[1,2]$. Cercetările în domeniul sănătății mintale au generat dovezi puternice care susțin că promovarea sănătății mintale și implementarea programelor de prevenție precoce, încă din perioada de preconcepție, pot influența factorii de risc pentru tulburările de sănătate mintală, având ca efect reducerea incidenței tulburărilor de sănătate mintală [10]. Medicul de famile poate face prevenție prin utilizarea unui instrument de mare valoare precum educația medicală. Cercetările au demonstrat că educația medicală reprezintă un determinant important al sănătății. Educația medicală este un factor important în prevenirea, diagnosticul și monitorizarea afecțiunilor netransmisibile, cum ar fi de exemplu bolile cronice, afecțiunile oncologice, bolile cardiovasculare și afecțiunile respiratorii cronice [11]. În acest context, prevenția tulburărilor de sănătate mintală prin educație medicală devine și mai valoroasă, cu atât mai mult cu cât este dovedit faptul că există o relație bidirecțională între bolile cronice și tulburările de sănătate mintală [12]. Medicul de familie face educație medicală atât femeii aflate în perioada de preconcepție, cât și femeii gravide. Comunicarea preventivă și îngrijirea prenatală la femeia aflată în perioada reproductivă și la femeia gravidă cuprind un plan bine structurat de evaluare a riscului, alcătuit din: evaluarea planului reproductiv, istoricul reproductiv, istoricul medical (de exemplu, prezența diabetului zaharat sau a hipertensiunii arteriale), medicamentele utilizate, infecțiile și imunizarea, screening-ul genetic și istoricul familial, evaluarea nutrițională, identificarea și consilierea în cazul abuzului de substanțe nepermise, expunerea la toxine sau substanțe teratogene, evaluarea factorilor de risc psihologici și sociali, evaluări clinice și paraclinice $[1,13,14]$. De asemenea, educația medicală la aceste două tipuri de paciente cuprinde și educația medicală pentru promovarea sănătății, cum ar fi de exemplu: promovarea comportamentelor sănătoase, greutatea ideală și nutriția sănătoasă, planning-ul familial, rezistența la stres, promovarea păstrării unui mediu înconjurător sănătos $[1,13,14]$.

Pornind de la datele din literatura de specialitate care susțin importanța educației medicale în prevenirea tulburărilor de sănătate mintală și implicarea activă a medicilor de familie în activitatea preventivă, ne propunem în cercetarea prezentată să identificăm disponibilitatea medicilor de familie din România de a comunica măsuri preventive pentru tulburările de sănătate mintală în timpul consultației la pacienta tânără aflată în perioada de preconcepție și la pacienta gravidă. În plus, ne dorim să identificăm care sunt barierele percepute de medicii de familie care au răspuns că nu au această disponibilitate.

\section{MATERIAL ŞI METODĂ}

\section{Metodă şi caracteristici chestionar}

Cercetarea de tip observațional, nonintervențională, a fost realizată în România, pe bază de chestionar completat online, pe una dintre platformele informatice utilizate de medicii de familie în cabinetul medical, pentru a-și înregistra activitatea medicală. Chestionarul a fost expus online la secțiunea "Chestionare" și a fost însoțit de o informare cu privire la scopul științific al chestionarului. Medicii de familie au răspuns voluntar prin accesarea neasistată a chestionarului. Răspunsurile au fost anonime și completarea chestionarului nu a fost condiționată de un anumit interval de timp. Chestionarul a fost pus la dispoziția medicilor care au dorit să participe timp de două săptămâni, pentru a-și exprima percepția cu privire la practica clinică personală.

\section{Lot țintă}

Participanții au fost medici de familie din 37 de județe din România. în intervalul de timp în care chestionarul a fost disponibil, au răspuns în total 153 de medici de familie, cu vârsta cuprinsă în intervalul 31-79 de ani (media 50,71 $\pm 9,7)$. Distribuția pe genuri a fost: 112 femei $(73,20 \%), 41$ bărbați $(26,80 \%)$, observându-se o mai mare paticipare a genului feminin comparativ $\mathrm{cu}$ genul masculin. Medicii de familie au provenit atât din mediul urban, $n=89$ (58,17\%), cât și din mediul rural, 
64 (41,83\%), cu superioritate numerică a respondenților din mediul urban.

\section{Analiza datelor}

Datele colectate au fost analizate folosind pachetul statistic Epi Info, versiunea 7, instrument de analiză statistică pus la dispoziție gratuit de CDC (Centers for Disease Control and Prevention) [15]. Pentru obținerea rezultatelor și analiză, s-au utilizat atât statistici descriptive (media și analiza frecvențelor), cât și statistică inferențială (cross tabulare - calculul coeficientului Chisquare).

\section{REZULTATE}

La intrebarea dacă fac educație medicală pentru prevenția tulburărilor de sănătate mintală la femeia tânără, în perioada fertilă, au răspuns 152 de medici. Acestia și-au exprimat disponibilitatea de a face educație medicală în timpul consultației la femeia tânără, în perioada fertilă, de preconcepție, pentru prevenția tulburărilor de sănătate mintală ale viitorului produs de concepție, astfel:

- $32,89 \%(n=50)$ dintre răspunsuri au fost afirmative;

- $67,11 \%(n=102)$ dintre răspunsuri au fost negative (Fig. 1).

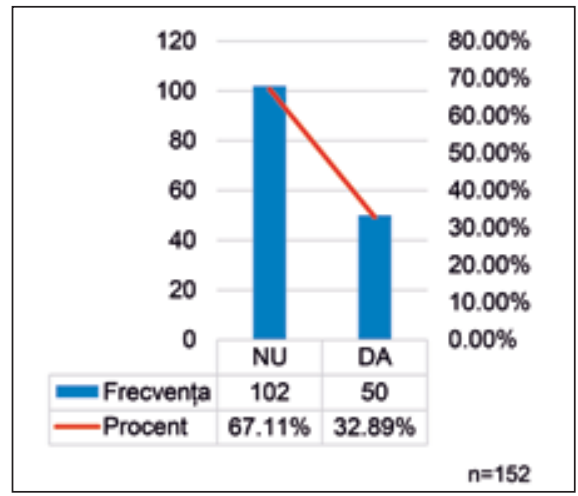

FIGURA 1. Frecvența și procentul răspunsurilor medicilor de familie la întrebarea dacă, în cursul consultației la femeia tânără, în perioada fertilă, de preconcepție, fac educație medicală pentru prevenția tulburărilor de sănătate mintală

Barierele percepute de medicii de familie în realizarea aceluiași demers au fost: $45,10 \%$ au ales „Nu, pentru că nu am instrumente de lucru necesare: chestionare, materiale educative pentru pacienți“, $22,55 \%$ au ales „Nu, pentru că nu cunosc tehnici de comunicare pentru astfel de situații”, $17,65 \%$ au ales „Nu, pentru că nu vin la mine cu astfel de întrebări“, 7,84\% au ales „Nu, pentru că nu am timp”, 3,92\% au ales „Nu, pentru că CNAS (Casa Națională de Asigurări de Sănătate) nu decontează astfel de servicii“, 2,94\% au ales „Nu, pentru că nu am cunoștințele necesare pentru a comunica cu astfel de pacienți“ (Fig. 2).

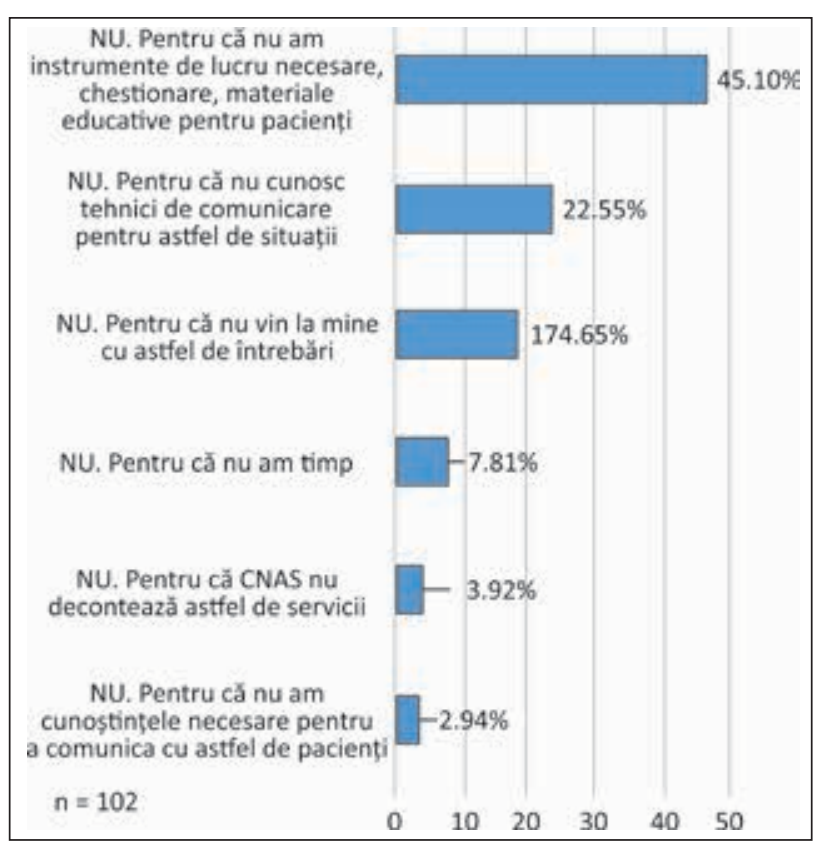

FIGURA 2. Bariere percepute de medicii de familie în realizarea educației medicale pentru prevenția tulburărilor de sănătate mintală la femeia tânără, în perioada fertilă, de preconcepție

La întrebarea dacă fac educație medicală pentru prevenția tulburărilor de sănătate mintală la femeia gravidă, au răspuns 152 de medici de familie. Aceștia și-au exprimat disponibilitatea de a face educație medicală în timpul consultației la femeia gravidă pentru prevenția tulburărilor de sănătate mintală ale viitorului produs de concepție, astfel:

- $41,45 \%(n=63)$ dintre răspunsuri au fost afirmative;

- $58,55 \%(n=89)$ dintre răspunsuri au fost negative (Fig. 3).

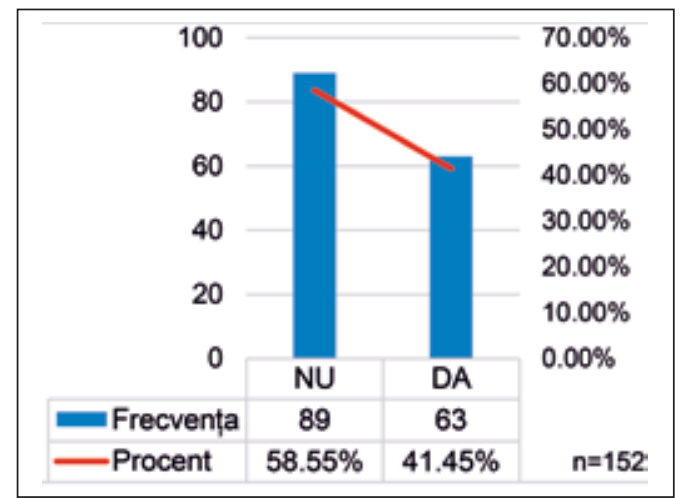

FIGURA 3. Frecvența și procentul răspunsurilor medicilor de familie la întrebarea dacă în cursul consultației la femeia gravidă fac educație medicală pentru prevenția tulburărilor de sănătate mintală

Motivele alese de către medicii de familie pentru răspunsul negativ relevă următoarele: $47,19 \%$ au răspuns „Nu, pentru că nu am instrumente de lucru necesare: chestionare, materiale educative pentru pacienți“, $22,47 \%$ au răspuns „Nu, pentru că nu cunosc tehnici de comunicare pentru astfel de situații", 14,61\% 
au răspuns „Nu, pentru că nu vin la mine cu astfel de întrebări“; 6,74\% au răspuns „Nu, pentru că nu este timp“, 5,62\% au răspuns "Nu, pentru că nu am cunoștințele necesare pentru a comunica cu astfel de pacienți“, 3,37\% au răspuns „Nu, pentru că CNAS (Casa Națională de Asigurări de Sănătate) nu decontează astfel de servicii“ (Fig. 4).

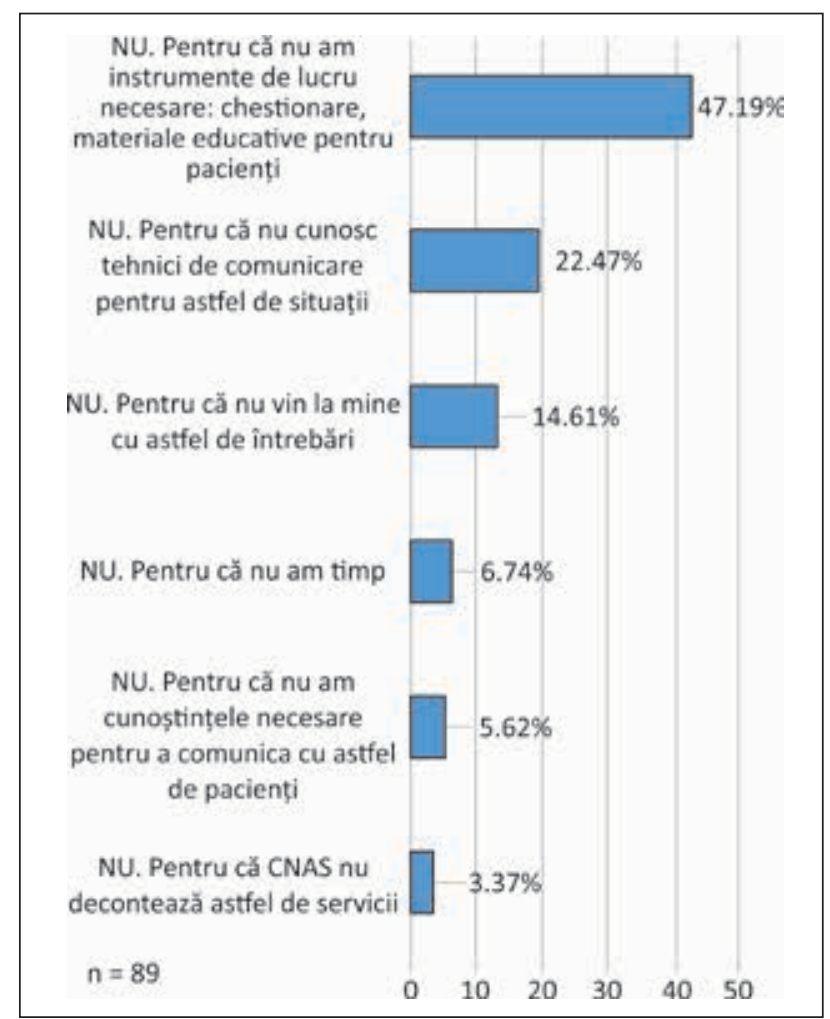

FIGURA 4. Bariere percepute de medicii de familie în demersul educației medicale pentru prevenție la femeia gravidă

Analiza statistică prin cross-tabulare a rezultatelor arată că există o asociere statistic pozitivă între disponibiltatea medicilor de familie de a face educație medicală pentru prevenția tulburărilor de sănătate mintală la femeia tânără, în perioada fertilă, de preconcepție, și disponibilitatea medicilor de familie de a face educație medicală pentru prevenția tulburărilor de sănătate mintală la femeia gravidă.

Analiza răspunsurilor negative indică o asociere semnificativă statistic între medicii care au ales răspunsul „nu, pentru că nu am instrumente de lucru necesare: chestionare, materiale educative pentru pacienți", atât la femeia tânără în preconcepție, cât și la femeia gravidă (testul Chi pătrat $=60,4608, p=0,000$ confirmă această asociere).

\section{DISCUȚII}

Prevenția tulburărilor de sănătate mintală, prin educație medicală, instituită precoce, încă din perioada de preconcepție, reprezintă o intervenție valoroasă, cu atât mai mult cu cât există numeroase dovezi care sus- țin că măsurile preventive aplicate cât mai devreme, încă din perioada de preconcepție, reduc riscul de apariție a tulburărilor de sănătate mintală la viitorul produs de concepție $[1,13,14]$.

Medicii de familie își arată disponibilitatea de a face educație medicală pentru prevenția tulburărilor de sănătate mintală atât la pacienta aflată în perioada de preconcepție, cât și la pacienta gravidă, dar în proporții diferite, procentul fiind mai mare în cazul prevenției la femeia gravidă. Această disponibilitate mai crescută în cazul femeii gravide poate fi justificată prin faptul că medicul de familie este implicat activ în monitorizarea femeii gravide, de la momentul confirmării sarcinii până la momentul nașterii și după naștere [1].

Una dintre barierele percepute de medicii de familie ca fiind motivul lipsei disponibilității de a face educație medicală în cursul consultației la ambele grupe de paciente este lipsa unor instrumente necesare: chestionare, materiale educative pentru pacienți. Al doilea motiv în clasamentul răspunsurilor negative a fost lipsa cunoașterii unor tehnici de comunicare pentru astfel de situații. lar al treilea motiv a fost faptul că pacientele nu solicită acest tip de informații. Este important de subliniat faptul că un procent mic dintre medicii de familie care au răspuns că nu fac educație medicală consideră că timpul reprezintă o barieră $(7,84 \%$ la pacienta în preconcepție și 6,74\% la femeia gravidă).

O proporție mică dintre medicii care au răspuns că nu fac educație medicală consideră că nu au cunoștințele necesare pentru a comunica cu astfel de pacienți (2,94\% la pacienta în preconcepție și 5,62\% la femeia gravidă).

Perioada perinatală reprezintă etapa din viața reproductivă a femeii caracterizată printr-o prevalență crescută a tulburărilor de sănătate mintală $[16,17]$. Prezența unei palete largi de tulburări mintale, de la depresie și anxietate până la tulburări de sănătate mintală precum schizofrenia, în această perioadă fragilă, poate afecta semnificativ dezvoltarea copilului, mama și familia [18-20].

Medicul de familie are un rol definitoriu în identificarea și managementul acestor paciente, fiind medicul de prim contact, care are acces total la istoricul pacientei și al familiei [21].

Raportul publicat de Centrul de Sănătate Mintală din Londra, în colaborare cu Royal College of General Practitioners, identifică o serie de bariere în oferirea îngrijirii corespunzătoare a femeii care prezintă tulburări de sănătate mintală în perioada perinatală, principala barieră fiind nivelul scăzut de identificare a nevoii de îngrijire. Raportul evidențiază, de asemenea, o serie de bariere în calea identificării nevoii de îngrijire, ca de exemplu: cursuri insuficiente și lipsa de încredere a medicilor de familie că pot gestiona astfel de situații, nivel de conștientizare redus al femeilor, partenerilor și fami- 
liilor lor legat de existența tulburărilor de sănătate mintală în perioada perinatală, teama femeilor legată de posibila stigmatizare și de faptul că bebelușul lor ar putea fi luat dacă își recunosc problemele de sănătate, precum și presiunea timpului în cursul consultațiilor pentru medicii de familie [22].

\section{CONCLUZII}

În urma analizei datelor, concluzionăm că disponibilitatea medicilor de familie de a comunica, prin educație medicală, măsuri preventive pentru tulburările de sănătate mintală la pacienta tânără aflată în perioada de preconcepție și pacienta gravidă este influențată de barierele percepute, precum lipsa instrumentelor de lucru necesare, sau de cunoașterea unor tehnici de comunicare pentru astfel de situații. De asemenea, disponibilitatea medicilor de familie ar fi diferită dacă pacientele ar iniția comunicarea în legătură cu aceste subiecte, prin întrebări, în cursul consultațiilor.

\section{Mulțumiri}

Mulțumesc echipei platformei icMed, care a contribuit la colectarea și prelucrarea datelor necesare acestei cercetări doctorale.

Conflict of interest: none declared

Financial support: none declared

\section{BIBLIOGRAFIE}

1. Matei $D$. Esenţialul în medicina de familie. Ed.a 3-a. București: Editura Amaltea, 2016.

2. Kidd M. The contribution of family medicine to improving health system. A guidebook from the world organization of family doctors. 2nd ed. London: Radcliffe, 2013.

3. World Health Organization. Mental Health: strengthening our response. Key facts. (30 March 2018). Avalable at: https://www.who. int/en/news-room/fact-sheets/detail/ mental-health-strengthening-our-response.

4. World Health Organization. mhGAP intervention guide for mental, neurological and substance use disorders in nonspecialized health settings: Mental Health Gap Action Programme (mhGAP),Geneva, 2010. Available at: https://www.who.int/mental_health/ publications/mhGAP_intervention_guide/en/.

5. World Health Organization and World Organization of Family Doctors. Integrating mental health into primary care: a global perspective. Geneva, 2008. Available at: https://www.who.int/mental_health/ resources/mentalhealth_PHC_2008.pdf.

6. Radu IA. Integrarea sănătăţii mintale la nivelul medicinei de familie - drumul de la mit la realitate. Ro J Pharm Pract. 2016;9(2):61-63.

7. Silverman JD, Kurtz SM, Draper J. Skills for communication with patients. 2nd ed. London: Radcliffe, 2005.

8. Kurtz SM, Silverman JD, Draper J. Teaching and Learning Communication Skills in Medicine. 2nd ed. London: Radcliffe, 2005.
9. Coll X, Papageorgiou A, Stanley A, Tarbuck A. Communication skills in mental health an introduction. CRC Press Taylor\&Francis Group, Boca Raton, 2012

10. World Health Organization. Prevention of mental disorders. Effective interventions and policy options. Geneva, 2004. Available at: https://www.who.int/mental_health/ publications/prevention_mh_2004/en/.

11. World Health Organization Regional Office for Europe. Health literacy The solid facts. Copenhaga, 2013.

12. World Health Organization and Calouste Gulbenkian Foundation. Integrating the response to mental disorders and other chronic diseases in health care systems. Geneva, World Health Organization, 2014. Available at: https://www.who.int/mental_ health/publications/gulbenkian_paper_ integrating_mental_disorders/en/.

13. Michael C. LU. Recommendations for Preconception Care. Am Fam Physician. 2007 Aug 1;76(3):397-400.

14. Narges Farahi, Adam Zolotor. Recommendations for Preconception Counseling and Care. Am Fam Physician. 2013 Oct 15;88(8):499-506.

15. Central for Disease Control and Prevention. Epi Info Downloads. https://www.cdc.gov/ epiinfo/support/downloads.html.

16. Noonan M, Galvin R, Doody O, Jomeen J. A qualitative meta-synthesis: public health nurses role in the identification and management of perinatal mental health problems. J Adv Nurs. 2017;73(3):545-57.
17. Fraser M Anderson, Stephani L Hatch, Carla Comacchio, Louise M Howard. Prevalence and risk of mental disorders in the perinatal period among migrant women: a systematic review and meta-analysis. Arch Womens Ment Health. 2017;20:449-462.

18. Bauer A, Parsonage M, Knapp M, lemmi V, Adelaja B, Hogg S. The costs of perinatal mental health problems. London School of Economics and Political Science, 2014. Available at: https://www.nwcscnsenate.nhs. uk/files/3914/7030/1256/Costs_of_perinatal_ mh.pdf.

19. Jones I, Chandra PS, Dazzan P, Howard LM. Perinatal mental health 2 bipolar disorder, affective psychosis, and schizophrenia in pregnancy and the postpartum period. Lancet. 2014; 384:1789-99.

20. Stein A, Pearson RM, Goodman SH, Rapa E, Rahman A, McCallum M, Howard L, Pariante CM. Perinatal mental health 3 effects of perinatal mental disorders on the fetus and child. Lancet. 2014;384:1800-19.

21. Tait $\mathrm{H}$, Heron J. Management of postnatal depression in primary care: a window of opportunity. Br J Gen Pract. 2010;60:801-2.

22. Khan L. Falling through the gaps: perinatal mental health and general practice. London: Centre for Mental Health; 2015. 